\title{
Innovative Power Systems and The Formation of The Creative Class in Russia
}

\author{
Alexander Y. Chmykhalo ${ }^{1,}$, , Vasilya R. Khaliulina ${ }^{1}$, Magipervas E. Abushaeva ${ }^{1}$ \\ ${ }^{1}$ National Research Tomsk Polytechnic University, 634050 Tomsk, Russia
}

\begin{abstract}
This article discusses the role of the post-industrial structures and the values associated with the formation of the creative class in the developed world, and the formation of the innovative economy. The formation of the creative class has had a decisive influence on the spread of new technical systems aimed at the response "activity" on the part of consumers, and on the organization of joint activities in their operation. Smart grids is one of the examples of such technical systems. In our analysis, we focused on identifying the correlation between the characteristics of the smart grid and the content value imperatives of the creative class, which could act as an emerging stimulus and development of such systems. We believe that the use of such technical systems in Russia is possible only as a result of the changes in the values of modern society, which are associated with the formation of the creative class.
\end{abstract}

\section{Introduction}

Designating the prospects of Russia in the near and distant future a number of Russian politicians and representatives of the expert community (for example, Dmitry Medvedev, Alexei Kudrin, German Gref and others.) point to the need to build an innovative economy. An innovative economy implies not only the presence of manufacturing companies producing modern high-tech products with high added value. A necessary condition of its formation is the presence of other elements of the county's innovation system - the higher education system (HES), effective public administration, corresponding to modern requirements, and the availability of infrastructure and social conditions for the functioning of complex technical systems, a large number of consumers of innovative products. Only under these conditions will the innovation economy have a foundation and prospects of its functioning and development.

The formation of an innovative economy in the developed world in the second half of the twentieth century occurred with the transition from industrial to post-industrial type of society in which a significant role was played by people of creative professions. To denote this group the American researcher R. Florida introduced the concept of the "creative class." R. Florida's view had been further developed in the whole complex of his works, which came later, as well as in the works of other authors (Tinagli I., Florida R., Ström P., Wahlqvist E., Clifton N., Rutten R., Gelissen J., Boschma RA, Fritsch M.). To date, the various aspects of the creative class, its role in the development of modern society have been disclosed in numerous studies that consider this phenomenon both internationally (Indergaard M., Murphy E., Redmond D., Stam E., Long P., Marlet G.), and at the regional level (Chapain C., Comunian R.) [1]. 
In his works R. Florida argues that the rise of the creative class is one of the most important features of post-industrial society. An increased role of representatives of the creative class in modern developed countries had a significant impact not only on the political, social, economic, technical and technological changes in recent decades, but also on the growing interest of a significant number of the population in seeking solutions to environmental problems, in discussing issues associated with the maintenance of the level and quality of life.

These interrelated processes are reflected in the actualization of interest in a wide range of scientific research work in the field of modern techniques and technologies, in particular, the development of smart grids.

In the present study, we examine the role of post-industrial structures and values associated with the formation of the creative class in the developed world at the end of XX and beginning of XXI century in the formation of the innovative economy. We believe that it is the creative class and the impact of value imperatives shared by them that have a determining influence on the use and broad dissemination of new technical systems aimed at consumers' response and organization of joint activities in their operation and development. Smart grids is one of the telling examples of such technical systems that have arisen in the developed world (oriented at innovative development) over the past decade.

In our analysis, we have focused on identifying the correlation between the characteristics of the smart grid and the content value imperatives of the creative class, which could act as a stimulus for emergence and development of such systems.

We believe that the possibility to use such technical systems in Russia is not determined by technical, financial, organizational, legal, or other methods and incentives. The use of modern technical systems in Russia and, as a consequence, the country's transition to an innovative path of development will only be possible if the value system of modern Russian society changes. The changes relate to the formation of the creative class, which includes not only the creators of scientific discoveries, the inventors of modern techniques and technologies, but also the consumers of innovative products.

The purpose of this paper is to analyze the world practice of creating and applying smart grids, and on this basis to justify the need to intensify the creative class formation in Russia as a condition for the creation and application of modern engineering systems, and as a consequence, facilitate Russia's transition to an innovative economy.

\section{Results and discussion}

Why do we choose smart grids as the main subject in the context of discussion of modern problems of interaction between science, technique, technology, and social development? The answer to this question can be found in the understanding of smart energy systems that is given in modern literature.

The generation of smart grids was spoken about as far back as in the 1970s. At that time, experiments to create "smart" networks, which later became known as Smart Grid (SMART stands for Self-Monitoring Analysis and Reporting Technology) were carried out simultaneously in the Soviet Union, the United States and Western Europe. This technology of self-diagnosis, analysis and report has been created to improve the reliability of equipment, and the ability to control it from a distance. Currently, different but close enough in meaning descriptions of the smart grid can be found in literature, for example :

- according to the EU technology platform for intellectual networks, the Smart Grid concept is defined as "an electricity network that can intelligently integrate the actions of all users connected to it - generators, consumers and those that do both - in order to efficiently deliver sustainable, economic and secure electricity supplies."[2]

- the definition offered by the USA Department of Energy reads as follows - the intelligent network is able to repair itself, creates an opportunity for active participation of consumers and actively responds to attacks and natural disasters, combines all the features of energy storage and 
production, makes it possible to introduce new products, services and markets, optimizes the use of devices and functions effectively, ensures quality electricity for digital economy $[3,4]$.

In the above definitions we can identify at least one thing in common. It consists in the emphasis that is placed on the consumer's active role in the construction and operation of the system. Consumers are meant not only to consume electricity, but also to create conditions for the development of this system. According to J.-P. Angelier, N. Hadjsaid, J.-C. Sabonnadière [5], in the present conditions of competition in the electric power supply, the dissonance between suppliers and consumers and the advent of new decentralized procedures for electricity production, distribution networks require specially adapted delivery architecture. There is a need for new restrictions, obligations and opportunities to improve the count of electricity consumed. In addition, the number of decision-makers regarding the functioning of the distribution networks involved in management has increased dramatically, but their goals do not always coinside. Leaders of distribution networks do not always have the financial resources necessary to better adapt to the new situation to improve the performance of networks in the long term. All of these conditions are the result of taking into account the impact of a set of constraints and solutions, economic and social characteristics of the time and, sometimes, the impact of political leadership.

Thus, the emergence of smart grids is caused not only by the technological advancement in the developed world in late XXth and early XXIst century, but also by social, economic and political incentives for development (decentralization of management, growing number of entities in the energy sector, requiring indiscriminating network access, limited financial resources, competition, high quality requirements of the services, liberalization of energy markets, the need to optimize the investments to improve safety, increase the need for power supply and so on [3]), which have transformed the lives of people in the developed world during the last three decades.

As a result, the European Commission has announced the electricity supply systems to be critical systems (necessary to maintain the life of society, to ensure health, safety, economic and social wellbeing), in addition to telecommunication systems, providing the population with fuel, water, public health, transport, etc. [6].

What gave rise to the formation of these incentives and led to their influence on the development of the smart grid? The formation of these incentives must be caused by the fundamental processes of social and economic changes that have occurred in modern developed countries in recent decades. They led to the formation of a new large social group - the creative class- that turned to be one of the main initiators, clients and customers of these systems. The influences of the changes are as follows:

- firstly, the ecological aspect. Representatives of the creative class (intellectuals, creative highly educated part of society) proved to be extremely demanding with regard to their living conditions. They are concerned not only with the living standard, but also with the quality of life, the presence of the necessary technical, socio-economic infrastructure to ensure the realization of their creative potential, improvement of the environmental situation in their place of residence. This circumstance has had a positive impact on expanding the use of alternative energy sources (photovoltaic, wind power);

- secondly, the educational aspect. Smart grids demanded new personnel, able to make decisions in a wide range of restrictions, high degree of responsibility for their decisions, the need to reconcile the conflicting interests of consumers and suppliers of energy and so on. This required higher level and quality of education of specialists to operate the power systems and implement systematic research. It is the high level of education in post-industrial countries that could provide the necessary experts to ensure the functioning of smart grids;

- thirdly, the creative aspect. The representatives of the creative class are the people whose occupations are associated with computer technology, architecture, engineering, design, art, media, entertainment, finance and others. These areas of activity have been highly dependent on the quality of services, including the supply of electricity. Those incidents, which occurred in the early $2000 \mathrm{~s}$ in Italy, Germany, USA, Canada, demonstrated the critical dependence of the functioning of modern society on electric power systems. This circumstance prompted the countries of Europe and America to improve the reliability of electricity infrastructure and to use renewable energy, energy efficiency; 
- fourthly, the social aspect. For the the creative class representatives one of the main characteristics of life satisfaction is to address the issues of social tolerance and openness to members of racial, ethnic and sexual minorities, the responsibility for the state of the place they live in. These issues would be impossible to solve without the activity on the part of the creative class representatives with respect to the revision of the value imperatives of modern society, without their intervention in issues of national and local significance.

Smart grids also proved to be very susceptible to the activity of the end user, without which they could not have been imagined. As part of the smart grid the consumer proved an active participant of the energy system, because they got a chance to regulate the load, production and accumulation of energy and so on [3];

- fifthly, the economic aspect. The representatives of the creative class found those sectors of economy attractive that allowed them to realize their creative potential. This fact gave rise to a new stage in the development of entrepreneurship, especially in the IT field and in the sphere of services. Among the aspects of the work on an enabling environment for small business development was the creation of the necessary infrastructure, including the provision of easy and equal access to energy systems for both large and small businesses.

All aforesaid demonstrates that due to the formation and activity of the creative class representatives there appeared the incentives, which, in turn, had a significant impact on the emergence and dissemination of smart grids.

The creative class representatives turned out to be the engine of economic advancement in today's developed countries, but they have had, and continue to have, a significant impact on changing social, legal, economic, cultural, technical and technological, environmental conditions in certain cities, regions and even countries.

Also, it is clear that attempts to implement and use modern technical systems in Russia, including smart grids, can only be successful if the conditions for the operation of similar incentives that influenced the formation of the smart grid in the Western European countries, USA, and Canada are created, i.e. if the value imperatives of the creative class can exert their transforming effect on the development of techniques and technologies, on innovation in Russia [7].

The presence of the creative class in Russia was mentioned by R. Florida in his preface to the Russian edition of the book "Creative class: people who change their future." (8)

However, some researchers have expressed certain doubts in relation to the quantity and quality of the part of the Russian population that could be attributed to the creative class (Bronzino L.) [9].

The Russian academic and publicistic literature presented the opinion that the Russian creative class can not be measured in quantitative terms, although there is some effort to do so (A. Okara). Moreover, the use of the term "creative class" in relation to the creative teams of the Russian population is not well established. Many authors use a completely different terminology. For instance, A. Okara uses the term "homo creativus» and refers it to such individuals that represent the psychological type of people with innovative potential and the ability to play a role in the economy (ie entrepreneurs, described by J.Schumpeter) [10].

In addition, a number of Russian researchers do not clearly distinguish characteristics of the creative class representatives from those of the middle class, estimating the size of the creative class on the basis of current estimates of the middle class in Russia (M. Gorshkov, Z. Golenkova, N. Tikhonova) [11].

The fact that currently the researchers do not clearly realize the presence of the already formed creative class in Russia demonstrates that this group has no significant influence on the development of social, political, economic, innovative processes in contemporary Russian society. It's amorphous blur is evident even where the concentration of creative people is so high that it would seem, should lead to a sharp increase in innovative activity, to the widespread use of new technical systems. For example, in the Tomsk region the concentration of highly skilled scientists is the greatest among all regions of the country (there are more than 5 thousand doctors and candidates of science). Also in Tomsk there is a scientific and educational complex (10 establishments realizing programs of higher education, 6 state universities, 6 institutes of Tomsk Scientific Center of the Siberian Branch of the 
Russian Academy of Sciences, 7 institutes of Tomsk Scientific Center of the Siberian Branch of the Russian Academy of Medical Sciences, 76 subjects of scientific activity) [12]. However, according to the Institute of Statistical Study and Knowledge Economy of "Higher School of Economics" as of 2014, the Tomsk region ranked only 8th for innovative development [13]. Although the development of intellectual power systems in Russia was initiated in Tomsk by creating the research center "Smart grids" in 2011 for the purpose of devising high-tech methods of heating, energy-supply and telecommunications, there hasn't been any significant breakthrough in the development of these systems either in the territory of the Tomsk region or in any region of Russia so far.

\section{Conclusion}

On the whole, the analysis shows that the prospect of using the advanced technology systems (like smart grids) in Russia can get a great chance to be implemented, providing the creative class makes significant changes in the control over further development of Russian society, and a greater influence of value imperatives which guide the organization of its life / and work, society as a whole. It is the expansion of creative class actions that is able to exert significant influence on the formation of incentives for the creation and widespread use of new technical means, on the transition to an innovation economy in which such systems are already playing a crucial role.

The article was supported by the Russian Humanitarian Science Foundation grant 15-03-14049.

\section{References}

1. R. Florida, C. Mellander, P. J. Rentfrow. The Happiness of Cities. Regional Studies, 47 (4), 613 (2013)

2. Smart Grids European Technology Platform. URL: http://www.smartgrids.eu/

3. N. Hadjsaid, J.-C. Sabonnadière. SmartGrids: Motivation, Stakes and Perspectives. ELTRACIGRE, 4 (2012)

4. Y.A. Salchak, D.A. Sednev, K.V.Krening, I.B. Ardashkin. IOP Conference Series: Materials Science and Engineering, 81, 1 (2015)

5. J.-P. Angelier, N. Hadjsaïd, J.-C. Revue de l'Energie, 60 (588), 77 (2009)

6. N. Hadjsaid, M. Viziteu, B. Rozel, R. Caire, J.-C. Sabonnadière et al. Interdependencies of coupled heterogeneous infrastructures: the case of ICT and Energy. 3rd International Disaster and Risk Conference. URL:https://hal.archives-ouvertes.fr/hal-00611581

7. I.B. Ardashkin, A.N. Yakovlev, N.V. Martyushev. Evaluation of the resource efficiency of foundry technologies: Methodological Aspect. Advanced Materials Research, 1040, 912 (2014)

8. R. Florida. The rise of the creative class. (Classic-XXI Publishing, Moscow, 2007)

9. L. Bronzino. Mediterranean Journal of Social Sciences, 6 (1), 200 (2015)

10. A. Okara The Creative Class as the Last Hope. Intellectual Russia, 9 (102), 12 (2009)

11. M. Gorshkov, Z. Golenkova, N. Tikhonova. The middle class in Russian society (Moscow: ROSSPEN, 1999)

12. A. Yu. Chmykhalo, Yu. R. Khasanshin (Hasanshin). Procedia - Social and Behavioral Sciences, 166, 497 (2015)

13. Rating innovative development of regions. URL: http://1tmn.ru/ratings/russia/opublikovanrejiting-innovacionnogo-4124528.html 